\title{
TraduÇão da Prima et SEConda LETtione da Edição de 1565 dos Elementos de Euclides Feita Por Niccolò TARTAglia
}

\author{
Carla Bromberg \\ Pesquisadora independente
}

(aceito para publicação em agosto de 2021)

\begin{abstract}
Resumo
Neste artigo iremos traduzir e analisar as duas lições (Prima et Seconda Lettione ${ }^{1}$ ) da segunda edição dos Elementos de Euclides traduzidos e editados por Niccolò Tartaglia em 1565. As lições versam sobre a classificação das ciências matemáticas puras e mistas, ou "dependentes", como Tartaglia as chama. Recorrendo aos filósofos que são considerados referências na definição e método de demonstração das ciências, assim como aos autores antigos e modernos, que representam as variadas ciências matemáticas, Tartaglia constroi sua argumentação, legitimando a sua proposta de classificação e a relevância das ciências matemáticas.
\end{abstract}

Palavras-chave: Niccolò Tartaglia, Ciências Mistas, Euclides, Tradução

\section{[Translation of the Prima et SEconda LetTione of Niccolò Euclide MEGARENSE (1565)]}

\begin{abstract}
In this article we will translate and analyse both lessons, Prima et Seconda lettione of the second edition of the Euclide Megarense (Euclid's Elements) which were translated and edited by Niccolò Tartaglia in 1565. The lezzione encompass the classification of mathematical sciences both pure and mixed - or dependent, as Tartaglia calls them. Calling upon philosophers, which are considered reference regarding the definition and demonstration method of the sciences, as well as authors, both ancient and modern, who

${ }^{1}$ Estou mantendo a grafia original da palavra como aparece nos documentos estudados, o mesmo para o nome do autor.


represent the pure and mixed mathematical sciences, Tartaglia builds his line of reasoning, legitimating his classification proposal and the relevance of the mathematical sciences.

Keywords: Niccolò Tartaglia, Mixed Sciences, Euclid, Translation.

\section{Introdução}

Niccolò Fontana (1500?-1557), mais conhecido como Tartaglia, foi um matemático do século XVI e autor da primeira tradução para o italiano ${ }^{2}$ da obra Os Elementos de Euclides. Afastando-se do idioma oficial dos escolásticos e eruditos, o latim, o autor defendeu o uso da língua vernacular e a difusão do douto conhecimento através dela.

Como se sabe, o século XVI foi palco de uma renovação na tradução de novos documentos, em sua maior parte diretamente do grego e do árabe e na proliferação das línguas vernaculares. O número de documentos traduzidos foi enorme, assim como a produção de textos focados no estudo dos processos de transmissão dos mesmos (Furlan, 2004). O Renascimento também foi o período no qual se estabeleceu a presença da técnica da impressão no ocidente. Esta viabilizou uma política editorial forte, constituída pela participação dos editores na forma final do texto, prezando a seleção e legitimação de obras pelas editoras.

Tartaglia, ao tranferir-se para Veneza, havia se mudado para o centro de publicação e editoração, talvez o mais importante da Itália de então; e participou, em várias de suas obras, como editor. ${ }^{3}$

A tradução dos Elementos de Euclides foi publicada em 1543 e reeditada em 1565 e $1569 .{ }^{4}$

Neste artigo, iremos traduzir e analisar as duas lições (Prima et Seconda Lettione) da segunda edição (1565, reproduzidas sem alterações significativas em 1569). As lições constituem, de forma conjunta, uma reelaboração dos textos introdutórios da primeira edição de 1543. Elas versam sobre a classificação das ciências matemáticas em puras e mistas ou como as chama Tartaglia, suas "dependentes". Citando textos que são considerados referências na definição e método de demonstração das ciências, e uma série de autores antigos e modernos, que representam as variadas ciências matemáticas, Tartaglia constroi sua argumentação, legitimando a sua proposta de classificação e a relevância das ciências matemáticas puras e mistas.

\footnotetext{
${ }^{2}$ Entre os séculos XIII e XVII (Duecento e o Seicento), a língua literária comum na Itália era o latim ou a língua vernacular de origem do autor. A partir do séc. XVI (Cinquecento), costuma-se chamar a língua literária de italiana, aquela que era basicamente de caráter fiorentino e toscano (Ageno, 1975).

${ }^{3}$ A maior parte de seus trabalhos foi publicada em Veneza através de tipografias de conterrâneos da Brescia: Venturino Ruffinelli, Nicolò Bascarini, Stefano Nicolini da Sabbio e Curzio Troiano Navò (Nova, 2000).

${ }^{4}$ Alguns estudos bibliográficos, como o de Riccardi (1887), acusam edições nos anos de 1544 e 1545, nem sempre verificadas por outros estudiosos (Favaro, 1913b; Heath ,1959; Thomas-Stanford, 1926; Wardbaugh 2020).
} 
Para podermos compreender a classificação das ciências, identificaremos as linguagens utilizadas, e as terminologias empregadas pelo autor. Elas são expressões de saberes específicos, e deste modo, delimitam áreas de conhecimentos pertinentes à época do autor. ${ }^{5}$ Acreditamos que saber relacionar a terminologia com as respectivas disciplinas e com a literatura de então é intrínseco e necessário ao trabalho da tradução.

Quanto ao aspecto filológico do texto, manteremos a transcrição fiel à grafia da impressão, mesmo sabendo que muitas vezes não deverá coincidir com a grafia do italiano moderno; ${ }^{6}$ separamos as palavras, que nos textos antigos muitas vezes aparecem ligadas, (com intuito de facilitar a leitura), mas manteremos a pontuação correspondente ao texto original, modificando-a somente na tradução para o português. Para além das mudanças sintáticas ou fonéticas, as mudanças de caráter semântico dos termos serão analisadas com o devido aparato na tradução. Cotejo das demais obras do autor, assim como das referências literárias, quando fornecidas por ele, além de dicionários da época proverão informações no decorrer da tradução.

Nosso trabalho não oferece uma tradução literal, ${ }^{7}$ nem uma edição crítica. Ele é um trabalho de natureza histórica. Histórico-filológica, na medida em que considera a linguagem e a fidelidade ao texto e seu contexto (Fontana, 1991). E de História da Ciência, no modo em que se atenta ao tratamento epistemológico que o autor dá aos conceitos e ao como desenvolve as discussões. Porque se preocupa com a contextualização, identificando as fontes e os diálogos com outras obras e agentes e por fim, porque considera os aspectos historiográficos nela envolvidos. ${ }^{8}$

\subsection{Tartaglia e os Elementos}

Niccolò Fontana (1500?-1557) era natural da Brescia, viveu em Verona e também em Veneza. Sabemos que se transferiu para Verona entre 1516 e 1519, tendo sido, a partir de 1518, mestre de ábaco (Masotti, 1959). Estabeleceu-se na cidade lagunar a partir de 1535, onde foi leitor público de matemática entre 1536 e 1548, lendo sobre Euclides na Basílica Dominicana de San Giovanni e Paolo. ${ }^{9}$ Retornou à Brescia brevemente, por um par de anos (1548-9) para voltar a viver em Veneza, onde faleceu em 13 de dezembro de 1557 (Pizzamiglio, 2004; Favaro, 1913b; Masotti, 1959).

Relatos biográficos, contemporâneos ao autor, são fornecidos em seus próprios textos (Tartaglia, 1546, 1556; Masotti, 1959; Pizzamiglio, 2004) e em biografias de

\footnotetext{
${ }^{5}$ Nestes tratados, as linguagens: natural, científica, matemática ou filosófica não estão caracterizadas de acordo com os nossos parâmetros hodiernos que, lembremos, estabelecem interfaces e limites diversos entre estas linguagens.

${ }^{6}$ Exceção feita ao 's' duplo, e a letra 'f', porque facilitam a correspondência entre fonética e grafia.

${ }^{7}$ A tradução não pretende ser literal, permitindo rearranjos morfossintáticos, ou seja, não presa pelo mesmo número de palavras na tradução, nem na mesma ordem sintática ou categorias gramaticais e pode não conter opções lexicais que possam ser tidas como sinônimos interlinguísticos (Aubert, 1998).

${ }^{8}$ Sobre a metodologia na história da ciência, vide: Alfonso-Goldfarb (2008); considerações sobre historiografia atualizada na história da matemática, vide: Roque (2012); Saito (2012, 2013).

${ }^{9}$ Tartaglia, 1556, Parte II, 41v.
} 
renascentistas, como Bernardino Baldi (1553-1617) e Ottavio Rossi (1570-1630). Estes últimos retratam Tartaglia como um homem de origem humilde, um grande entendido da Aritmética e da Geometria ${ }^{10}$ e um homem inventivo.

Com relação à obra de Euclides, ambas as narrativas biográficas demostram uma relação entre o papel do autor, como leitor da Matemática em Veneza, com a obra e a tradução dos Elementos de Euclides, feita por ele em 1543 (Baldi, 1707). Segundo Rossi, as obras de Tartaglia teriam se espalhado pela Europa e em especial, a tradução de Euclides teria sido muito bem recebida:

"Não é necessário demonstrar o quanto Tartaglia era um bom matemático, porque suas obras ilustres estão por toda a Europa, e seu Euclides é obra estimadíssima, assim como aquelas sobre suas tantas invenções." ${ }^{11}$ (Rossi, $1620,386)$

Em $1543^{12}$, Tartaglia publicou a sua tradução de Euclide Megarens ${ }^{13}$, que foi a primeira tradução, no ocidente, para uma lingua vernacular europeia (Riccardi, 1887; Favaro,1913b; Heath,1959; Masotti, 1959).

Na sua primeira obra, Nova Scientia (1537) o autor fez referências a inúmeros trechos da obra de Euclides ${ }^{14}$, porém sem comentar a necessidade ou a vontade de realizar uma tradução.

Para a publicação de um livro em Veneza, havia a necessidade de uma licença a ser concedida. Haveria um pedido (supplica) e uma deliberação (deliberazione). Na literatura, os estudiosos de Tartaglia atestam não ter encontrado documentação sobre o pedido (Tonni-Bazza 1903; Favaro 1913a), mas sobre a deliberação, datada de 1542. Nela, se deliberam as publicações da tradução de Euclides, de Arquimedes, e uma correção da Summa Arithmetica et Geometrica de Pacioli. ${ }^{15}$

10 “[..] percioche il Tartaglia con un ostinatissimo studio rese padrone si può operare intorno ad ogni specie di Matematica", (Rossi, 1620, p.13). "Nicolò Tartaglia Bresciano d'humile nascimento attese alle cose Matematiche e particolarmente alla Geometria \& all'Aritmetica con tanto genio, che si lasciò molti adietro", (Baldi, 1707, p.133).

11 “Quanto fusse buon Mathematico il Tartaglia non hà bisogno d'alcuna dimostratione; percioche viuono le opere sue illustri per tutta l'Europa essendo stimatissimo il suo Euclide e i libri di quelle altre sue tante inventioni, [..]”

12 Antes da publicação de Euclide Megarense, havia sido publicada apenas a Nuova Scientia, 1537.

13 Venezia, tip. Venturino Ruffinelli, editori Guglielmo di Montefeltro, Pietro Facolo, Niccolò Tartaglia. No mesmo ano e pela mesma tipografia, a obra de Arquimedes, Opera Archimedis Syracvsani philosophi et mathematici ingeniosissimi, Venezia, tip.Venturino Ruffinelli, ed. Niccolò Tartaglia. A obra traz, da tradução latina de Moerbecke (séc. XIII), os seguintes escritos: De centris gravium libri duo, Tetragonismus ovvero De quadratura circuli e De insidentibus aquae. Esta obra é considerada pelos estudiosos uma cópia da edição latina do napolitano Luca Guarico, publicada em Veneza no ano de 1503. Vide: Dijksterhuis, (1938).

14 Os livros dos Elementos aos quais fez menções são os livros, I, II, III,V e VI.

${ }^{15}$ Estamos adotando o título da obra de Pacioli como aparece no documento que foi transcrito por Tonni-Vazza, 1903. O título completo sendo Summa di Arithmetica, Geometria, Proportioni et Proportionalità. No mesmo documento há também deliberação para uma obra de ‘Horone o philosopho'. Senato I. Registro 32. Terra 15421543.

RBHM, Vol. 21, n 42, pp. 146-179, 2021 
Dos motivos que o levaram à tradução, acredita-se, como mencionado anteriormente, que o texto servisse a sua leitura pública. Tartaglia considerava o texto de Euclides propício ao ensino e sua tradução para o italiano visava difundir a obra para um maior número de pessoas (Tartaglia, 1543, 1565; Rose, 1975; Gavagna, 2010). No seu proêmio, após expôr abertamente as fraquezas da tradução de Campano, criticando sua tentativa em elucidar certas definições do tratado Euclideano, Tartaglia conclui que este as teria tornado tão mais confusas, que somente poderia induzir o estudante ao abandono do estudo (Tartaglia, 1543, fol. III, linhas 18-20). Para Tartaglia, esta, dentre outras causas, explicaria os motivos pelo qual estava disposto a traduzir a obra para o italiano (Tartaglia, 1543, fol.III, linhas 26-31).

Na segunda edição (1565), na carta dedicatória de autoria do editor Curtio Troiano de Navò, Tartaglia é elogiado, 'o grande entendedor das matemáticas' e sua obra, um motivo de orgulho para o editor. Segundo Navò, Tartaglia teria sido o único a compreender a sutileza e as obscuridades das sentenças de Euclides, e os verdadeiros fundamentos da matemática, contrariamente aqueles que anteriormente haviam se lançado a este propósito.

Embora houvesse um número razoável de edições parciais ou totais dos Elementos de Euclide $^{16}$ (Riccardi, 1887; Gavagna, 2009), Tartaglia comentou, tanto, na introdução da edição de 1543, como, de forma menos direta, no último parágrafo da Segunda Lição (1565), que teria se utilizado das versões de Giovanni Campano e de Bartolomeo Zamberti. Na segunda edição, dirigindo-se aos auditores, afirmou que as edições de Euclides (que estes provavelmente deveriam conhecer) eram as 'duas traduções que estavam a seu dispôr"17, ou seja, as de Campano e de Zamberti ("que ainda estava vivo"). ${ }^{18} \mathrm{O}$ autor mencionou conhecer também as edições dos Elementos, publicadas em Paris (1516) ${ }^{19}$, que foi a primeira edição a publicar conjuntamente ambas as versões (Campano e Zamberti) e a publicada na Alemanha (Tartaglia, 1565; Heath, 1956).

Ao valer-se do vernacular, Tartaglia defendia a grande estatura da língua italiana para a transmissão de conhecimento douto e portanto, a considerava apta às ciências matemáticas (Tartaglia, 1543 e Cartelli; Piotti, 1998; Marchi, 2007). ${ }^{20}$

\footnotetext{
${ }^{16}$ Riccardi, 1887, p.12-16.

${ }^{17}$ Apesar dos títulos das obras trazerem a informação de que as traduções teriam sido feitas do latim.

${ }^{18}$ A primeira tradução, do árabe para o latim, da obra Os Elementos foi realizada por Adelhard de Bath por volta do ano de 1120. Campano de Novara, matemático, astrônomo e médico teria se baseado na tradução de Adelhard para realizar a sua tradução do árabe da obra de Euclides, publicada em Veneza, por Erhard Ratdolt em 1482 (Heath, 1921, 1956; De Risi, 2016; Enciclopedia Italiana, 1929). A primeira tradução feita diretamente do grego para o latim, sobre um manuscrito de Theon, foi a realizada por Bartolomeo Zamberti (1473-?) e publicada em 1505.

${ }^{19}$ Tendo sido reeditada em 1537 e 1546 em Basel (Riccardi, 1887; Heath, 1956; Wardhaugh, 2020)

${ }^{20}$ Em outras instâncias, como no Cartelli, Tartaglia voltaria a defender o uso do vernacular na ciência. Tartaglia, Na Seconda risposta data da Nicolò Tartaglia Brisian a Messer Lodovico Ferraro delle Mathematice Lettor pubblico [...] al detto Excellente Signor Hieronimo Cardano et al eccellente Messer Lodovico Ferraro suo Creato.
} 


\subsection{Da classificação e da certeza das Ciências Matemáticas}

Tartaglia discorreu nas duas lições sobre a classificação das ciências matemáticas, que, segundo ele, incluíam as matemáticas puras, suas dependentes e as mecânicas. O sistema, por ele apresentado, é uma modificação ampliada do grupo das artes liberais que originalmente eram sete: trivium (Retórica, Dialética e Gramática) e o quadrivium (Aritmética, Geometria, Música e Astronomia) (Freedman, 1999; Weisheipl, 1978). Do trivium, Tartaglia nomeou apenas a Dialética, ${ }^{21}$ e a partir das ciências matemáticas, apresentou as ciências subalternas, que ele chamou de ciências dependentes ou médias (Tartaglia 1543, 1565, 1569).

Tartaglia já havia incluído, no frontispício da Nova Scientia (1537), uma imagem com um esquema de classificação do conhecimento incluindo personagens como Euclides, Aristóteles, Platão e ele próprio. Na imagem, o Quadrivium foi representado com a figura de Tartaglia ao lado da Geometria e da Aritmética e, à sua frente, a Astronomia e a Música. Dizeres iluminam as figuras, e versam sobre a certidão das matemáticas, explicando que para aqueles que quisessem conhecer as várias causas das coisas, as matemáticas seriam o único caminho (Qui cupitis rerum varias cognoscere causa, discite nos: cunctis hac patet una via) e sobre a imprescindível necessidade de se conhecer a Geometria (Nemo huc geometriae expers ingrediatur). Aristóteles e Platão participam no grupo, representando respectivamente as ciências médias e a pureza especulativa, Euclides, a Geometria e no ponto supremo do círculo (Aurum probatur igni, et ingenium mathematicis) encontra-se a Filosofia (Pizzamiglio 2004; Valleriani, 2013).

No Euclide Megarense, publicado seis anos após a Nova Scientia, Tartaglia novamente iniciou a obra provendo uma classificação das ciências matemáticas e de suas dependentes.

Na edição de $1543,{ }^{22}$ Tartaglia apresentou a Geometria como ciência necessária, incluindo posteriormente a Aritmética, sua 'irmã', reconhecendo-as como princípio da sabedoria. A partir delas, dividiu as demais ciências em dois grupos, o das artes liberais e o das mecânicas (fol. III). A classificação das disciplinas/ciências se desenvolveu de forma dissertativa, com considerações sobre a natureza dos entes matemáticos e das entidades físicas, e sobre a sua forma de apreensão, sugerindo serem pensados como intermediários entre os aspectos inteligíveis puros e os aspectos sensíveis.

Nas edições posteriores, Tartaglia abreviou e modificou o texto introdutório de 1543, afastando-o do contexto da natureza dos objetos matemáticos. Dividiu-o em duas lições, e o estruturou com parágrafos numerados apresentando individualmente cada ciência matemática dependente, reiterando a certeza das ciências matemáticas.

Na segunda lição, Tartaglia deixou transparecer que a dificuldade de conhecimentos das ciências matemáticas e do discernimento entre as puras e suas

\footnotetext{
${ }^{21}$ Tartaglia não menciona fontes, nem contextualiza Platão com relação às disciplinas. Contudo, a citação da Dialética individualmente, sem o contexto do trivium, possa ser considerada, como quando na República, Platão apresenta a matemática como um grau preliminar da dialética (República VI, 510B)

${ }^{22}$ Para o estudo da primeira versão e outras obras de Tartaglia veja, neste mesmo volume, o artigo de Eduardo Kickhofel e Henrique Marins de Carvalho, “Cartas-prefácio de Tartaglia: matemáticas práticas no século XVI”.
} 
dependentes, poderiam estar relacionados à má compreensão de textos importantes como a Física, a Metafísica, os Analíticos Posteriores e o Do Céu de Aristóteles. Como se sabe, as observações de Aristóteles mais significativas com relação à metodologia das ciências subalternas estavam em alguns dos livros nomeados por Tartaglia, nos Analíticos Posteriores, na Física e na Metafisica. ${ }^{23}$ Além do próprio filósofo, no Renascimento, eram utilizados, principalmente, os comentários dessas obras, através dos escritos de Tomás de Aquino $^{24}$ e Averróes (Mueller,1981; Nascimento e Pich, 2013).

De acordo com a noção aristotélica de ciência, as ciências subalternas (que Tartaglia chama de dependentes) são as mais naturais das ciências matemáticas. Elas emprestam os primeiros princípios das ciências puras (Aritmética ou Geometria), usam estes princípios e demonstrações matemáticos para chegarem a conclusões sobre coisas físicas. Elas não demonstram através de causas e seus sujeitos implicam coisas naturais. Contudo, as propriedades do objeto da ciência subalterna não são puramente físicas, elas são propriedades que as matemáticas puras estudam de forma abstrata (Nascimento 1995, Nascimento e Pich, 2013).

Embora Tartaglia reitere o caráter dependente das ciências com relação às ciências puras, somente uma destas ciências está caracterizada por seus objetos e terminologia específicos. O exemplo, mais direto de uma ciência subalterna fornecido no texto, está no parágrafo 6, no qual o autor aborda a Música, a sua primeira ciência dependente. Ele descreve a relação de expressão dos intervalos musicais por razões, mostrando que a ciência subalterna não considera todo o fenômeno físico, nem todos os seus aspectos, mas aquilo que nele pode ser matematizado (Bromberg, 2017).

É importante notar, que esta matematização tem por base, noções de objetos abstratos, vis-à-vis objetos reais e naturais e relações entre conhecimentos matemáticos teóricos e práticos, que em última análise, refletem uma convicção metafísica de que tudo no mundo foi criado a partir de medidas e números. A matemática envolvida nas ciências subalternadas, como podemos perceber claramente na Música e na Mecânica, é incompleta, dado que não consegue explicá-las satisfatoriamente (Roux, 2010; Bromberg, 2014a). ${ }^{25}$

Com relação à importância da demonstração das ciências subalternas, Tartaglia faz duas menções (somente uma delas está nas lições). A primeira menção está na segunda lição, no parágrafo introdutório, no qual ele diz que, segundo Aristóteles, conhecer intelectualmente se daria através da demonstração. ${ }^{26} \mathrm{~A}$ segunda menção está no comentário à definição 22, do livro I dos Elementos, quando afirma que os primeiros princípios de

${ }^{23}$ Também nas obras: Da alma II, Meteorológica III.2 e III.4; As Partes dos Animais I.1; De sensu.

${ }^{24}$ Comentário ao Tratado da Trindade de Boécio (Expositivo super librum boethii de Trintate).

${ }^{25}$ Neste sentido não existe sinonímia entre as ciências mistas/subalternadas/ intermediárias e as matemáticas aplicadas dos séculos posteriores. Essas ciências requerem a transformação da matemática, enquanto a noção de matemática aplicada está baseada na ideia de que existem certos procedimentos matemáticos que não precisam ser transformados para dar explicações satisfatórias dos fenômenos em consideração. Para uma discussão mais ampla vide: Roux (2010).

${ }^{26}$ Como se sabe, na noção de ciência aristotélica, conhecer é conhecer o fato e o porquê. A verdade da ciência deve ser demonstrativa, mas os primeiros princípios não, por serem indemonstráveis, mas necessários e suficientes. 
qualquer ciência não se conheceriam por demonstração e que nenhuma ciência deveria ter que provar os seus primeiros princípios, porque o teria de fazer ad infinitum (Tartaglia 1565, 1569).

Tartaglia não pormenoriza o tema da demonstração, nem sua relação com o grau de certeza das matemáticas. Contudo, como se sabe, em 1547 Alessandro Piccolomini já havia publicado o seu texto Commentarium de certitudine mathematicarum, e as discussões sobre a forma pela qual as ciências subalternas se diferenciavam das ciências puras estavam aquecidas. Neste sentido, haveria posteriormente dois métodos capazes de atestar a certeza da matemática: a demonstração silogística e a axiomática, cujas caraterísticas epistemológicas, os tipos de objetos e a maneira como estes objetos estariam relacionados; diferiam (Giacobbe, 1972; Mueller, 1981, Kelleher, 1991).

Como se vê nas lições, Tartaglia não se aprofundou, nem em discussões sobre a noção de demonstração, nem da natureza dos objetos; não obstante, pareceu compreender que os objetos eram, em última análise, objetos racionais, diferindo apenas no fato de serem vistos qua sensíveis ou qua matemáticos.

Com relação às fontes, Tartaglia não é explícito. Sabemos apenas das citações de obras de autores mencionados por ele no texto. Como vimos anteriormente, havia na deliberação para a publicação do Euclide Megarense uma licença para a publicação de uma correção da obra Summa de Pacioli. Levando em conta esta informação, podemos assumir que Tartaglia teria estado em bastante contato com os textos de Pacioli. A familiaridade com os textos de Pacioli aparece também nas críticas que Tartaglia faz ao autor em sua obra, principalmente no seu General Trattato di numeri et misure (1556). Assim, no decorrer da tradução, indicaremos os trechos semelhantes aos de Pacioli.

Com relação aos textos das lições, na Primeira Lição, Tartaglia apresentou rapidamente, ao mencionar Platão e Aristóteles as formas do saber, citando a Metafísica de Aristóteles (livros 1 e 2).

Nos parágrafos 2, 3 e 4, apresentou as três causas pelas quais as ciências/artes/disciplinas matemáticas deveriam ser as primeiras na ordem do saber: porque os saberes teóricos e práticos se completam, um não podendo existir sem o outro (cita Vitrúvio, Os Dez livros de Arquitetura, Livro I, cap. 1). Porque se sustentam a si próprias, por demonstração, e porque as demais ciências matemáticas (as dependentes) delas dependem.

A partir do parágrafo 5, no qual aparecem a Aritmética e a Geometria em Euclides, o autor segue com as disciplinas que delas dependem: 6) Música, 7) Astronomia, 8) Astrologia e Magia, 9) Geografia, 10) Corografia, 11) Perspectiva e Especulária, 12) Pintura, 13) Horológica, 14) Ciência dos Pesos, 15) exalta Arquimedes (Mecânica), 16) arte Militar, 17) 18) e 19) elogio aos historiadores e tratadistas de Guerra como Vegetio e Frontino, 20) Arquitetura, 21) Boécio e a Matemática como disciplina propedêutica à Filosofia, 22) Boécio e Platão, e a Geometria como primeira ciência, 23) da importância de se conhecerem as matemáticas para compreender bem Aristóteles, 24) Álgebra, 25) do saber contar e da racionalidade do homem, 26) Dialética, 27) Ciência das Leis, 28) Teologia, 29) recorre à concepção metafísica de que Deus é a medida de todas as coisas. 
Algumas destas ciências já apareceram na edição de 1543. Contudo, nesta última, o contexto, ou seja, o embasamento teórico, filosófico, a concatenação de autores, o estabelecimento de relações entre diferentes ciências apresentou-se modificado. Por exemplo, as classificações da Geometria e da Aritmética. Na primeira edição, o autor parte do pressuposto da primazia da Geometria sobre a Aritmética, enquanto na segunda edição aparecem argumentos que discutem a hierarquia. Ao classificar a Música, Tartaglia citou Franchinno Gaffurio (1451-1522), um importante teórico do século XV-XVI. Na edição de 1543 ele defendeu que, sem os números, as proporções e a proporcionalidade não seria possível distinguir a consonância da dissonância. Na edição de 1565/1569, diferentemente da primeira, Tartaglia recorreu à Gaffurio na definição de ponto. A definição determinava que um ponto fosse aquilo que não possuía partes. Tartaglia completava que o ponto seria para a geometria o que a unidade era para a aritmética, ou seja, um princípio do número, e não um número; assim como na música era o som. ${ }^{27}$

Na Segunda lição, Tartaglia resumiu as primeiras mudanças do quadrivium clássico, deixando de lado a lista expandida de conhecimento dos leigos, passou ao quadrivium clássico de Sevério N. Boécio (470-525) e Giorgio Valla (1447-1500). A estas ciências matemáticas foi por vezes adicionada a Perspectiva, como defendido por Luca Pacioli (ca. 1445-1517), ou excluída a Música. Mas, ao final, ele concluía com Euclides, que as matemáticas puras seriam somente duas, a Aritmética e a Geometria (Tartaglia, 1565, fols. 5v-6r). Ele demonstrou, citando a Metafísica, Do Céu, e principalmente o segundo livro da Física de Aristóteles, defender que o matemático, ao contrário do filósofo natural, baseado na razão, consideraria as coisas separadamente da matéria e parte para a definição de ponto.

\section{Bibliografia}

AGENO, Franca B. 1975. L'edizione critica dei testi volgari. Padova. Antenore.

ALFONSO-GOLDFARB, A. M. 2008. Centenário Simão Mathias. Documentos, Métodos e Identidade da História da Ciência. Circumscribere 4, pp. 5-9.

AUBERT, Francis. H. 1998. Modalidades de tradução. Teoria e resultados.In: TradTerm 5 (1), 99-128.

BALDI, Bernardino. 1707. Cronica dei matematici ovvero Epitome dell'istoria delle vite loro, Urbino, Angelo Ant. Monticelli.

BERTATO, Fábio. 2008. A “De Divina Proportione: de Luca Pacioli. Tradução anotada e comentada.Tese de Doutorado. UNICAMP, Campinas.

${ }^{27}$ Os parágrafos cujo conteúdo é semelhante ao texto da primeira edição são, nesta ordem: 7,6,8,25,5,11,9,27,28,29,30. 
2010. De Divina Proportione de Luca Pacioli - Tradução anotada e comentada, Campinas: Coleção CLE, vol.56.

, 2011. Contribuições dos pensamentos Medieval e Renascentista para o desenvolvimento da Matemática. In: Revista Brasileira de História da Matemática. vol.11, n.23, Anais IX SNHM, pp.27-38.

BORGATO, Maria Teresa. 1981. Alcune note storiche sugli "Elementi" di Euclide nell'insegnamento della matematica in Italia. In: Archimede, fasc.4, 185-193.

BROMBERG, Carla. 2012. As Artes Liberais entre o medievo e o renascimento. In: Maria Helena Roxo-Beltran; Fumikazu Saito, Laís Trindade (orgs.). História da Ciência: Tópicos Atuais 2. São Paulo: Livraria da Física, 1-21.

, 2014a. Os objetos da Música e da Matemática e a subalternação das Ciências em alguns tratados de Música do século XVI. In: Trans/Form/Ação. v.37, n.1, 9-30.

, 2014b. The Mathematical Status of Music and Architecture in the Works of Daniele Barbaro. Paper presented at Scientiae, Berlin.

, 2017. Niccolò Tartaglia e a Música. In: Actas/Anais do 7 Encontro LusoBrasileiro de História da Matemática, Óbidos, 1-13.

De MORGAN, Augustus. 1847. Arithmetical Books from the Invention of Printing to the Present Time. London: Taylor and Walton.

De RISI,Vincenzo. 2016. The development of Euclidean axiomatics. The systems of principles and the foundations of mathematics in editions of the Elements in the Early Modern Age. In: Archives for the History of Exact Sciences 70, 591-676.

DIJKSTERHUIS, Eduard J. 1938. Archimedes. Princenton, NJ: Princeton University Press, red. 1987

FAVARO, Antonio. 1913a. Di Niccolò Tartaglia e della stampa di alcune delle sue opere con particolare riguardo alla Travagliata Inventione. In: Isis vol.1, n.3, 329-340.

LXXI, 335-372.

1913b. Per la biografia di Niccolò Tartaglia. In: Archivo Storico Italiano,

FOLENA, Gianfranco. 1991. Volgarizzare e tradurre. Torino, Einaudi. 
FOLKERTS, Menso. 2006. Regiomontanus' Approach to Euclid. In: M. FOLKERTS, The Development of Mathematics in Medieval Europe: The Arabs, Euclid, Regiomontanus. Aldershot: Ashgate.

FREEDMAN, J. S. 1999. Philosophy and the Arts in Central Europe, 1500-1700: Teaching and Texts at School and Universities. Vermont/Aldershot: Brookfield.

GAVAGNA, Veronica. 2009. La tradizione euclidea nel Rinascimento. In: The Euclidean, $1-10$.

97-123. 2010. Euclide a Venezia. In: Pacioli 500 anni dopo. Veneza, Aboca Edizioni, , 2012. "Di ben intendere senza le Euclideane Istruttioni, niun certo si puo avantare“: Tartaglia e gli Elementi, XII Congresso SISM, Università Cattolica. Brescia.

GIACOBBE, Giulio C. 1972. Il Commentarium de certitudine mathematicarum disciplinarum di Alessandro Piccolomini. Physis 14, 357-74.

GRAFTON, Anthony. 2005. The Magic and Technology in Early Modern Europe. Washington, DC: Smithsonian Institution Libraries.

GRASSI, Giuseppe. 1833. Dizionario militare italiano, 4 vols., Torino. Società Tipografico Libraria.

HEATH, Thomas L. 1921. A History of Greek Mathematics. vol.1. Oxford.

HEATH, Thomas L. 1956. The Thirteen Books of the Elements, vol. I. New York: Dover. KELLEHER, 1991.

MANCOSU, Paolo. 1992. Aristotelian Logic and Euclidean Mathematics: Seventeenth Century Developments of the Quaestio de Certitudine Mathematicarum.In: Studies in the History and Philosophy of Science, vol.23, n.2, 241-265.

MARCHI, Mario. 2007. L'insegnamento di Euclide in N. Tartaglia: analisi di una scelta. In: Ateneo di Brescia, Atti della Giornata di Studio in Memorie di Niccolò Tartaglia nel 450 anniversario ella sua norte dicembre 1557-20007. (ed.) Pierluigi Pizzamiglio, 13-20.

MASI, Michael. 1983. Boethian Number Theory: A Translation of the De Institutione Arithmetica. Rodopi, Amsterdam (Studies in Classical Antiquity, vol. 6).

MASOTTI, Arnaldo. 1959. Rarità tartagliane. Spigolature bibliografiche e archivistiche. In: Atti del Convegno di Storia delle Matematiche a cura di Arnaldo Masotti, 119-160. 
, 1962. Studi su Niccolò Tartaglia. Brescia. Ateneo di Brescia.

McKIRAHAN, Richard D. 1978. Aristotle’s Subordinate Sciences. In: British Journal for the History of Science, vol.11, n.2, 197-220.

MONTEIRO, João Gouveia. 2008. Vegécio e os sons da reforma militar romana: por um futuro cheio de passado.In: Revista de História das Ideias, vol.29, 9-39.

NASCIMENTO, Carlos A. 1995. De Tomás de Aquino a Galileu. Campinas:UNICAMP.

65. , 2007. Tomás de Aquino e as Ciências Intermediárias. In: Aquinate, n. 4, 55-

NASCIMENTO, Carlos A.; PICH, Hofmeister, Roberto. (org.). 2013. As ciências intermediárias: algumas sondagens históricas. Vol. II. ediPUCRS/ Editora Fi. Porto Alegre.

NOVA, Giuseppe. 2000. Stampatori, librai ed editori bresciani in Italia nel Cinquecento. Fondazione Civiltà Bresciana, Brescia.

PIOTTI, Mario. 1998. La lingua di Niccolò Tartaglia. La “Nova scientia” e i "Quesiti et inventioni diverse”. Milano. LED.

PIZZAMIGLIO, Pierluigi. 2004. Niccolò Tartaglia. In: Nuova Secondaria, n.7, 1-16. , 2005. Niccolò Tartaglia (1500ca.-1557) nella storiografia. Acc. Naz. di Scienze e Lettere e Arti di Modena. In: Atti e memorie. Memorie Scientifiche, giuridiche, letterarie, s.VIII, v.VIII, fasc.II, 443-453.

Brescia.

, 2012. Niccolò Tartaglia nella Storia con antologia degli scritti. EDUCatt,

RICCARDI, Pietro. 1870. Biblioteca matematica italiana dalla origine dela stampa ai primi anni del secolo 19.

e Parmeggiani.

1887. Saggio di una bibliografia Euclideana. Bologna, Tipografia Gamberini

ROQUE, Tatiana. 2012. A História da Matemática. Uma visão crítica desfazendo mitos e lendas. Rio de Janeiro: Jorge Zahar Editora.

ROSE, Paul.L. 1975. The Italian Renaissance of Mathematics. Geneve: Librarie Droz. 
ROSSI, Ottavio. 1620. Elogi historici di bresciani illustri teatro da Ottavio Rossi. Brescia, Bartolomeo Fontana, 386-387.

ROSSI, Paolo. 1989. Os Filósofos e as Máquinas. Tradução Federico Carotti. Sâo Paulo: Companhia das Letras.

ROUX, Sophie. 2010. Forms of Mathematization (14th-17th Centuries). In: Early Science and Medicine, vol.15, 319-337.

SAITO, Fumikazu (2012).

TARTAGLIA, Nicolò. 1537. Nova Scientia inventa da Nicolo Tartalea. Veneza: Stephano da Sabio.

1543. Euclide Megarense philosopho, solo introduttore delle scientie mathematice, diligentemente reassettato, et alla integrità ridotto per il degno professore de tal scientie Nicolo Tartalea, Brisciano, secondo le due tradottioni ; e per commune commodo \& utilita de latino in volgar tadotto ; con una ampla espositione dello istesso tradottore di nouo aggionta ; talmente chiara, che ogni mediocre ingegno, senza la notitia, ouer suffragio di alcun'altra scientia con facilita, sera capice à poterlo intendere, per Venturino Roffinelli ad instantia e requisitione de Guilielmo de Monferra, \& de Pietro di Facolo da Vinegia libraro, \& de Nicolo Tartalea Brisciano tradottore.

, 1543. Opera Archimedis. Venturino Ruffinelli. Venezia.

, 1546. Quesiti et inuentioni diverse de Nicolo Tartalea Brisciano, Venise : Venturino Ruffinelli.

, 1556. General Trattato, Venice per Curtio Troiano dei Navò.

1565. Euclide Megarense philosopho, solo introduttore delle scientie mathematiche: diligentemente reassettato, et alla integrità ridotto per [...] Nicolo Tartalea [...] e per commune commodo \& utilità di latino in volgar tradotto. Con una ampla espositione dello istesso tradottore di novo agionta [...], Venise: Curtio Troiano dei Nauò.

THOMAS-STANFORD, Charles. 1926. Early Editions of Euclid's Elements, London.

TONNI-BAZZA, Vincenzo. 1904. Frammenti di nuove ricerche intorno a Nicolò Tartaglia. In: Atti del Congresso Internazionale di Scienze Storiche vol. XII, Roma, Tip. della R. Acc. dei Lincei, 293-307. 
WARDHAUH, Benjamin. 2020. Euclid in print, 1482-1703. A catalogue of the editions of the Elements and the other Euclidean works.

WEISHEIPL, J. A. 1978. The Nature, Scope and Classification of the Sciences.In: Science in the Middle Ages (ed.) David C. Lindberg. Chicago: The University of Chicago Press.

WOLFF, Francis. 2004. Ciência Aristotélica e Matemática Euclideana. In: Analytica vol.8, n.1, 44-88.

VALLA, Giorgio. 1501. Georgii Vallae Placentini, de expendentis et fugiendis rebus ec. (Di geometria, libri VI. in quibus elementorum Euclidis difficultates omnes fere exponuntur ec.) Venetiis, in aedibus Aldi Romani.

VALLERIANI, Matteo. 2013. Metallurgy, Ballistics and Epistemic Instruments. The Nova Scientia of Niccolò Tartaglia. A New Edition. Max Planck Research Library for the History and Development of Knowledge. Sources 6. Berlin. Edition Open Access.

\section{Carla Bromberg}

São Paulo - Brasil

E-mail: carlabromberg@gmail.com 


\title{
2. Tradução
}

\subsection{Primeira Lição}

(fol.3r)

\author{
Lição de Nicolo Tartalea Bresciano, \\ sobre toda a obra de EVCLIDE, Megarense ${ }^{28}$, \\ Acvtissimo Matematico
}

1 Todos os homens, Magníficos e Precatíssimos Au-|ditores, (como escreve Aristóteles no primeiro li-|vro da Metafísica) desejam, naturalmente, o saber ${ }^{29}$. O [filósofo] | no primeiro livro dos Analíticos Posteriores conclui, que o saber | não é outra coisa que não o compreender por de-|monstração ${ }^{30}$. Para Platão, a sabedoria não é outro | que não a cognição das coisas divinas e humanas. E | todos os antigos filósofos dizem, as partes da sabedoria serem duas: a especulativa e a operacional. | Ou seja, a Teórica e a Prática. Aristóteles, no segundo | livro da Metafísica, diz que a finalidade da ciência Especulativa | não é outra, que não a verdade; enquanto a da ciência operacional, | ou Prática, a finalização da obra. Os antigos estudiosos ainda a-|firmam, como a verdade é efetiva na disciplina matemática, mais do | que em qualquer outra ciência ou arte liberal ${ }^{31}$. Pois eles a determinam | com o maior grau de certeza. Porém, vejamos (como diz o Cardeal | de Cusa) todos aqueles, que gostam destas disciplinas, aproximarem-|se delas com admirável amor, (e não poderia ser de outra forma), | dado que contêm o verdadeiro alimento da vida intelectual.

2 Tais ciências, ou disciplinas, são tão intrinsicamente | conhecidas dos nossos antigos estudiosos, que por eles | foi determinado, que a primeira coisa a ser aprendida, por | todos

\footnotetext{
28 Tartaglia se referiu a Euclides como àquele de Megara (ca. 435-ca. 365AC), ao invés de Euclides de Alexandria. A troca dos nomes era comum nos tratados da época. Segundo Heath (1956) a confusão entre os Euclides pode ter se iniciado com o autor Valerius Maximus, e foi transmitida pela tradução dos Elementos feita por Bartolomeo Zamberti. Demais autores descreveram Euclides como o megarense, dentre eles Pacioli (Venice, 1509), Faber (Paris, 1512), Finé (Paris, 1544). Foi somente com a versão dos Elementos publicada por Frederico Commandino, em1572, que a confusão foi resolvida.

${ }^{29}$ Metaphysica I, 1, 980a, 1 e Metaphysica I, 2, 982b, 12.

30 Aristóteles, nos Analíticos Posteriores afirma que "conhecer [cientificamente] o quê difere de conhecer [cientificamente] o porquê”, isto é, o conhecimento do fato (hóti, “o quê”) é distinto do conhecimento da razão do fato (dióti, "porquê”). Para ele, o conhecimento científico (epistémê) é obtido pela demonstração (apódeixis), que por sua vez significa um silogismo (“dedução”). Considera, portanto, dois tipos de demonstrações distintas: demonstração do fato (apódeixis tou hóti) e demonstração da razão do fato (apódeixis tou dióti) (Bertato, 2011).

${ }^{31}$ Alberti, Da Divina Proportione, isso significa que as ciências e disciplinas matemáticas estão no primeiro grau de certeza e a estas se seguem todas as ciências naturais.
} 
aqueles que se dedicam à busca do conhecimento, fosse as | disciplinas matemáticas (como hoje é costume fazer com a Gramática). | Esta determinação constitui-se por três causas: a primeira, porque as | ditas ciências ou disciplinas, aprovam a engenhosidade do homem. Se | ele está apto, ou não, a frutificar nas demais ciências. Como se dizia no | provérbio Sicut aurum probatur ingni, \& ingenium matematicis. Isto é, | como a pureza ${ }^{32}$ do ouro é conhecida e verificada com o fogo, | assim a engenhosidade do homem é conhecida e | aprovada com as disciplinas matemáticas. E ainda assim, se | encontrassem alguém, que manualmente não fosse capaz para tal ciência, o levariam | de tal estudo, apenas iniciado, aplicando-o a outro exercício, | porque com efeito compreendiam (como diz Vitrúvio Polione, no | primeiro capítulo, do primeiro livro) que a doutrina sem o engenho, | (fol.3v) ou o engenho sem a doutrina, não podem fazer um artesão perfeito.

3 A segunda causa, porque os nossos antigos queriam que as | Matemáticas fossem as disciplinas a serem primeiro estudadas é esta: | porque à inteligência daqueles não é necessária nenhuma outra ciência. A causa é | que [essas disciplinas] por si só se sustentam, se verificam e por | si só se provam. Não por [argumento de] autoridade ou opinião | dos homens, como ocorre com as demais ciências, mas por | demonstração.

4 A terceira causa é que sabiam, que as demais ciências, artes | ou disciplinas, necessitavam da matemática. Não [me refiro] so-|mente às Artes Liberais e suas dependentes, mas também às Artes mecânicas, como em breve, se mostrará.

5 Primeiramente ele nota que, por meio destas tais ciências, | ou disciplinas, é através de sua ocorrência na natureza que conhe-|cemos sua descrição, sua qualidade e a quan-| tidade de cada figura geométrica, seja um triângulo, um quadrado, | um pentágono, um hexágono, rombos e romboides ${ }^{33}$ ou qualquer | outra figura plana. Da mesma forma conhecemos se um corpo | sólido é regular, ou irregular, como são as pirâmides, os prismas, | os prismas triângulares ${ }^{34}$, os cones, os cilindros ou colunas, os cubos, os $\mid$ octaedros, dodecaedros, isocaedros e outros iguais, com todas as | suas propriedades e proporções, como descreve geometricamente | o nosso autor Euclides, em seus quinze livros, dos quais onze são de | geometria (os livros 1,3,4,6,10,11,12,13,14, e o 15). Três são de | aritmética, os livros 7, 8 e 9, sendo o quinto comum a ambas [geo-|metria e aritmética] dado que trata da proporção e da proporciona-|lidade, tanto aplicadas ao número quanto à medida.

\footnotetext{
${ }^{32}$ Bontà é um termo que aparece com variados significados, podendo ser "boa qualidade”, no sentido de pureza, essência. Na expressão, com relação à pureza do ouro, o Vocabolario della crusca indica relação com o termo assagiare, (Lat. periculum facere) (1 ed., pg. 84).

33 Do termo grego rhomboeidés que significa: semelhante ao losango. São quadriláteros nos quais as diagonais são perpendiculares, mas não se cortam pelo meio como no paralelogramo.

${ }^{34}$ Cossali (1857).
} 
6 Certo é que essas tais ciências, ou disciplinas matemáticas | nutrem ${ }^{35}$, são mães dos músicos. Dado que, com seus núme-|ros e com as proporções e a propriedade da proporcionalidade, | nos fazem conhecer a proporção dupla, chamada pelos práticos de oitava, | ser composta de uma sesquiterça e de uma sesquiáltera. Assim, | como nos faz saber que a sesquiterça é composta de dois tons, e de | um semitom menor, e a sesquiáltera ser composta de três tons e | de um semitom menor. Assim como, a dita [razão] dupla se manifesta | na oitava, que é composta de cinco tons e dois semitons menores. | Ou seja, uma coma a menos do que seis tons. Sabemos também, que o tom | é mais que oito e menos que nove . Novamente, pelo vigor de tais disciplinas, sabemos ser impos-|sível dividir o tom, ou qualquer outra razão superparticular em duas par-|tes iguais (o que demonstra o nosso Euclides, na oitava proposição do li-|vro oitavo). ${ }^{36}$

7 Ainda há a escassez de bons e excelentes astrônomos, não por outra | razão, que por defeito das disciplinas acima mencionadas ${ }^{37}$. I Porque, como diz Giovanni de Monte Reggio $^{38}$, certamente ninguém pode avançar | se não entender bem o Almagesto de Ptolomeu, e sem | as instruções Euclideanas. Embora se leia no Eclesiástico, | primeiro capítulo: Altitudinem coeli, \& latitudinem terrae, \& profundu | abissi quis dimensus est? ? $^{39}$ Não obstante, tanta é a virtude destas ciências, | ou disciplinas, que através das proporções, não somente os | nossos antigos conheceram quanto a Terra era redonda, | quanto fosse o seu diâmetro, mas também outros elementos, | como a grandeza do Sol, da Lua, das estrelas (móveis e imóveis), | a formação de céu, como demonstra Ptolomeu, no Almagesto | e Alfonso, em suas tabelas ${ }^{40}$.

\footnotetext{
${ }^{35}$ A tradução mais literal deveria manter um substantivo, que no caso significaria uma "ama" ou "ama de leite". Boécio, em sua obra De Istitutione Arithmetica, diz que a Aritmética ocupa um lugar previlegiado na posição de mãe das demais ciências $(1,1,8)$.

${ }^{36}$ Tartaglia desenvolve aqui uma argumentação na qual parece conhecer a relação entre as proposições VII.33 (do tratado Sectio Canonis de Ps.Euclides) e VIII.8 dos Elementos de Euclides, que tratam da divisão em partes iguais de intervalos musicais expressos por proporções superparticulares. Para uma discussão mais aprofundada sobre o tema da música na obra do autor, vide Bromberg (2017).

${ }^{37}$ Em Alberti, A Divina Proportione, “Nem por outra razão há penúria de bons astrônomos, senão pelo defeito de aritmética, geometria, proporções e proporcionalidades” (trad., Bertato, p.9).

${ }^{38}$ Johann Müller Regiomontanus (1436-1476), matemátio, astrônomo, frequentou o círculo do cardeal Bessarione e conhecia sua biblioteca e seus manuscritos gregos. Criou em Nuremberg uma editora para a publicação de textos matemáticos, geográficos e astronômicos. Trabalhou sobre uma edição dos Elementos de Euclides em seu Programma editorial, basenado-se na versão de Campano. Ratdolt, editor de Campano, havia trabalhado na tipografia de Regiomontano (Folkerts, 2006).

${ }^{39}$ O Eclesiásticos é um dos livros deuterocanônicos presente na Septuaginta, o conjunto de sete livros da antiga tradução grega do texto hebraico do Antigo Testamento. No Cap. I, segundo verso, lemos na sua forma completa: Arenam maris, et pluviae guttas, et dies saeculi quis dinumeravit? Altitudinem coeli, et latitudinem terrae, et profundum abyssi quis dimensus est? (A areia do mar, as gotas da chuva e os dias do século [da eternidade]. Quem os contou? Da altura do céu, da largura da terra, e da profundidade do abismo? Quem os mediu?)
} 
8 Essas mesmas ciências, ou disciplinas, ainda forjaram o caminho | à arte da Astrologia Judicial $^{41}$, dita Astrologia, assim como à Piromancia, Hidroman-|cia, Geomancia, Necromancia ${ }^{42}$, e outros feitiços como escreve Isido-|ro [de Sevilha], Cieco Dascoli ${ }^{43}$ e de forma similar, Cornelio Agrippa no | segundo livro da [obra] Occulta Philosophia ${ }^{44}$.

9 O que iremos dizer sobre a Geografia? Não demonstra Ptolomeu e | todos os demais excelentes geógrafos, quanto seja necessário o nú-|mero, a medida, a proporção e a proporcionalidade! Quando, todas | as coisas do universo, devidamente proporcionadas [através] dos graus | da longueza e largura, em um pequeno pedaço de papel, reduz todas | as famosas províncias, cidades, castelos, rios, ilhas, penínsulas e outros | locais marinhos e mediterrâneos.

10 Quando essas coisas são necessárias à Corografia? ${ }^{45}$ Ou seja, ao | modo de se desenhar corretamente um local, ou país e | de forma semelhante a planta de uma cidade, como demonstramos | no quinto livro da nossa [obra] Quesiti et inventioni diverse.

11 Novamente, considerando bem e estudando a ciência Perspectiva, | sem dúvida percebemos que ela nada seria, se não fosse a sua mãe, | a Geometria. Isso pode ser verificado, não apenas em Euclides, na sua | Especulária e Perpectiva, mas também com o Arcebispo Giovanne Cantuariense, | e amplamente com Viteleno ${ }^{46}$, um grande perspectivo, cujas proposições | são aprovadas e demonstradas de acordo com as proposições de Euclides.

\footnotetext{
40 Alfonso X, rei de Leão e Castela entre 1252-1284, foi responsável por incentivar trabalhos de tradução sobre astronomia e astrologia, incluindo também a comissão de novos textos.

${ }^{41}$ A astrologia, por vezes também chamada de Giudiciaria, era considerada por muitos uma arte quimérica, utilizada para prever o futuro, mas não englobava todo o conteúdo estudado pela astrologia e não devia ser confundida com a astronomia, que era a ciência que estudava os céus. Ver: Astrologia ottima indifferente, pessima. Censure pubblicate dal P. Gian Battista Noceto. Compagnia di Giesu. Parigi, MDCLXIII.

${ }^{42}$ Essas ciências eram chamadas de ciências da adivinhação desde Sto. Agostinho e retransmitidas dentre outros, por Isidoro de Sevilha e Hugo de São Victor.

${ }^{43}$ Francesco Stabili di Simeone (1269-1327). Suas obras foram escritas em latim, destinadas à sua atividade didática. Dentre elas, o Tractatus in sphaeram (1322-23), comentário de um tratado inglês, e De principiis astrologiae (1323-24) comentário de uma nota astronômica árabe de Al-Kabisi.

${ }^{44}$ Vale lembrar que a obra De occulta Philosophia Libri tres, de Henry Cornelius Agrippa, está listada nos catálogos de obras sobre Aritmética, vide: De Morgan (1847).

${ }^{45}$ Ciência que se refere hoje à Topografia.

${ }^{46}$ Tartaglia se refere ao polonês Vitelo, filósofo natural, anatomista, fisiologista, filósofo e perspectivo ativo durante a segunda metade do século XIII. Sua obra Peri-Optikes (ou Perspectiva) foi publicada pela primeira vez, em Nurembergue, no ano de 1535.
} 
12 Que estas ciências, ou disciplinas, sejam necessárias à arte da Pin-|tura, não necessito provar. Me basta que Alberto Dürer, excelente pintor | de nossa época, não somente confessa e afirma, mas o demonstra $\mid$ aos sentidos ${ }^{47}$.

13 Quanto estas [ciências] sejam oportunas à arte Horologica, | ou seja, à composição, descrição e construção dos relógios, tanto | horizontais quanto nos murais. Sebastião Mustero não somente em | prática, mas teoricamente já o manifestou.

14 Destas mesmas disciplinas brota e nasce a ciência dos | pesos. Como abertamente demonstra Giordano em Ponderibus, | que também retificamos e aprovamos no nosso quinto livro | do nosso Quesiti et Inventioni diverse com a ciência, que | Aristóteles, em sua [obra] Questões Mecânicas, atribui à causa | de cada invenção mecânica.

15 A virtude, ou potência dessas tais disciplinas é tão unânime | e certa, que Arquimedes de Siracusa, ao estudá-las, defendeu, com | suas engenhosas invenções mecânicas, a cidade de Siracusa | contra o avanço de Marco Marcelo ${ }^{48}$, cônsul romano, fato que o | imortalizou. $^{49}$

16 Por meio delas se fazem vários e diversos modelos, fabricam-se | pontes quase impossíveis à natureza.

17 Além disso se, com o intelecto, consideramos e vemos todo | tipo de máquina (antiga e moderna), ou instrumento bélico (de ata-|que ou defesa), como são os bastiões, ${ }^{50}$ repari,

\footnotetext{
${ }^{47}$ Tartaglia cita Dürer relacionando a Pintura às matemáticas puras. Enquanto na Summa, Pacioli relaciona os pintores à Perspectiva, citando outros, que não Dürer.

${ }^{48}$ Marcus Claudius Marcellus (c.268-208 AC) foi cônsul e procônsul da República Romana inúmeras vezes e general do exército, do qual estava à frente na época da conquista de Siracusa.

${ }^{49}$ Alberti, Da Divina Proportione, "não menos do que pela própria pátria fez o nobre e engenhoso geômetra e digníssimo arquiteto Arquimedes. Este, como está escrito, com suas novas e várias invenções de máquinas, por longo tempo salvou incolume a cidade siracusana contra o ímpeto e belicoso avanço dos romanos, quando abertamente tentaram expugná-la, sob o comando de Marco Marcelo”, (trad. Bertato, 2008, p.7).

${ }^{50}$ Bastione, do francês (Bastion). Pode ser um engenho de ataque ou defesa. Se de ataque, se assemelha a torre de cerco, de forma quadrada ou circular, móvel que era aproximada às muralhas trazendo escadas e soldados, ou armas. Se de defesa, refere-se a um tipo de construção, que se excede em volume, avançando com relação às paredes das muralhas servindo como elemento defensivo da fortificação. Poderia ter diferentes formas planimétricas e tinha por objetivo proteger a fortificação com as cortinas, que eram as partes da fortificação mais expostas ao ataque inimigo, permitindo o alojamento de artilharia (Grassi, vol. 1, p.227).
} 
bricole $^{51}$, trabucos ${ }^{52}$, catapultas, | escorpiões ${ }^{53}$, balistas $^{54}$, ariete ${ }^{55}$, restudine, torres de cerco | (como demonstra Vitrúvio no livro 10) ${ }^{56}$. Construídos com a força dos | números, da medida e das proporções também são | descritos por Vegetio ${ }^{57}$, Valturio ${ }^{58}$ e Leão Batista Alberti.

18 Das novas invenções, por nós descobertas, com relação | às máquinas infernais modernas, chamadas pelo vulgo, de artilharia, | nada repetirei, por já haver dito e publicado em outra parte ${ }^{59}$. Bas-|ta somente dizer, que por conselho destes, sem nenhuma experiência | prática nesse exercício, a maior parte eu encontrei.

19 De forma semelhante e em virtude destes, decidimos executar | todos aqueles modos (narrados por Vegetio e Frontino Valturio ${ }^{60}$ ), | que utilizavam os nossos antigos ao ordenar de diversas formas os exércitos em batalha, isso é de forma quadrada de gente ou de

${ }^{51}$ O termo bricole também significa catapulta (Grassi,1833, vol.1, p.292).

52 Trabuco, termo do francês (Trébut). Nome diverso para a mesma máquina chamada de balista pelos romanos. Tipo de catapulta que arremessava grandes pesos em fogo (Grassi, 1833, vol.4, p.270). Ele é um engenho de contrapeso ou tração animal/humana, enquanto a balista é um engenho de torção de cordas.

53 Termo do latim (Scorpio). Instrumento romano militar antigo que podia lançar até duas pequenas setas. No tempo de Vegetio foi chamado de Manubalista (Grassi, 1833, vol.4, p.65).

${ }^{54} \mathrm{O}$ termo baliste, como já mencionado, é uma catapulta. A catapulta originalmente lançava somente setas ou instrumentos perfurantes, enquanto a balista, lançava pesos. Ela era utilizada majoritariamente para defesa. A balista e o escorpião são citados em várias edições de Vitrúvio, Os Dez livros de Arquitetura, sempre no livro X, capítulo 10, os demais armamentos, nem sempre. Acredita-se que a importância de se recorrer ao tratado de Vitrúvio, não seria pela nomeação dos engenhos, mas pela explicação do funcionamento dos engenhos de tração de cordas, dado que era o saber 'afinar' essas cordas, que garantiria atingir a precisão de lançamento necessária.

${ }^{55} \mathrm{O}$ Ariete era o único dos engenhos de ataque, ou destruição que se destinava ao ataque direto das muralhas ou portões, era uma arma somente de ataque, ao contrário das catapultas, balistas, bricoles. Era um instrumento que deveria ficar suspenso ou por cordas ou por correntes (Grassi, 1833, vol.1-2, p.102).

${ }^{56}$ Este parágrafo tem semelhança com Pacioli, na Divina Proportione (trad. Bertato, 2008, p.8) com relação à listagem das máquinas, contudo Pacioli as legitima através de tradição textual recorrendo aos escritos históricos de Lívio, Dionísio e Plínio.

${ }^{57}$ Publio Flavio Vegecio Renato escreveu a obra Epitoma Rei Militares (Compêndio de Técnica Militar). O autor teria escrito a obra para reavivar a honra do exército romano e incentivar os imperadores romanos às reformas militares necessárias. A obra deve ter sido escrita após a derrota de Adrianopla. Discorre sobre a seleção de soldados dentre os cidadãos, o treino e analisa problemas como a disposição dos acampamentos e os preparativos para batalha, as dificuldades com o terreno, como atravessar rios, e variantes táticas de ataque, retirada e perseguição, dentre outras (Monteiro, 2008)

${ }^{58}$ Roberto Valturio (1405-1475) foi um escritor, conhecia bem latim e grego e escreveu De re militari (1460).

${ }^{59}$ Nova Scientia.

${ }^{60}$ A obra de Valturio, De re militari, foi reeditada inúmeras vezes. Ela constituía uma narrativa anedótica das guerras antigas, uma espécie de Stratagemmi de Frontino. 
terreno $^{61}$. | Como também o modo de formar o cuneo $^{62}$, a fórfice ${ }^{63}$, a sega ${ }^{64}$, o rhumbo ${ }^{65}$, a | forma circular e lunar, coisas que ao presente tempo já foram perdidas.

20 De quanta ajuda e subsídio estas ciências fornecem à Arquitetura, | Vitrúvio manifesta no Proêmio de sua obra ${ }^{66}$.

21 Estas tais ciências, ou disciplinas, não somente aguçam a engenhosidade | do homem, como o torna apto a penetrar, com facilidade, em qualquer | outra ciência que queira. Mas, ainda o preparam para ser capaz de discorrer $\mid$ sobre o conhecimento. Por isso, Boécio quer que estas disciplinas sejam o | próprio meio de ascensão àquelas, finalmente concluindo que sem estas, | (5r) tais ciências, ou disciplinas, seria impossível filosofar de forma correta ${ }^{67}$.

22 O mesmo pode ter sido corrigido com efeito, por Platão, | pai e mestre dos filósofos. O qual não queria que,| dos alunos que entrassem na sua escola, ou estúdio, não fosse | algum que não fora entendido na geometria.

23 E não devemos nos maravilhar, se muitas das passagens na Física, | Metafísica, Analíticos Posteriores de Aristóteles, assim como no Céu, | que parecem [obras]obscuras e difíceis aos nossos modernos, o seja | não por outra razão, que a falta do saber de tais disciplinas.

24 Essas mesmas dão origem à Prática especulativa da Ál-|gebra, ou Almucabala, vulgarmente chamada de regra das coisas | ou Arte Magna. E isto, não somente Maomé,

\footnotetext{
${ }^{61} \mathrm{O}$ corpo de soldados podia ser organizado de duas formas: quadrado de gente, no qual o arranjo dos homens se dava em formato quadrado, ou seja, com número igual de homens para cada lado, ou quadrado de terreno, no qual a largura do grupo de homens era duas vezes e um terço maior que o comprimento (Grassi,1833. vol.3, p.293). Estas formações seriam discutidas na obra Quesiti (primeiro e quinto).

${ }^{62}$ Sob o verbete puntone: definição 5, do Lat. cuneus (Vocabolario della crusca, 3 ed., vol.3, p.1283)

63 Sob o verbete forbice (Lat. Forfex). Nome de uma ordenação militar romana, imitada pelos italianos nos primeiros séculos de sua milícia. Tem formato de uma tesoura aberta. (Grassi, 1833, vol.2, p.150)

${ }^{64}$ Sega, do Latim (Serra). Nome de uma ordenação dos soldados, como se fossem colocados juntos numa série de cuneos (Grassi, 1833, vol.4, p.74).

${ }^{65}$ Rhumbo pode também ser forma de trapézio (Cossali, 1857).

${ }^{66}$ De acordo com a historiografia tradicional, o Trattato di architettura de Francesco G. Martini (1439-1501) foi um dos primeiros a resgatar à arquitetura sua teoria, fundamentando-a como arte liberal, e a versão de Cesare Cesariano (1475-1543), publicada em 1521, foi a primeira em língua vernacular. A obra de Vitrúvio foi vastamente comentada entre os séculos XV e XVII. Estes comentários foram extremamente divulgados e utilizados na época pelos estudiosos, assim, é importante, ao dirigir-nos a estes séculos, sabermos especificar qual das traduções comentadas estamos utilizando.

${ }^{67}$ Para Boécio, as ciências matemáticas constituíam-se num instrumento de alcance da filosofia, designadas como um grupo de disciplinas de caráter propedêutico (Masi, 1983).
} 
filho de Moisés- o | àrabe (primeiro inventor de tal ciência), mas também Frade Luca | dal Borgo, Michel Stifelio e Leonardo Pisano o manifestam | geometricamente.

25 Tendo, o divino Platão, sido interrogado um dia, do porque ser $\mid$ o homem, dentre o gênero animal, o animal chamado de racional, | enquanto todos os demais eram chamados de irracionais e brutos,| ele respondeu: porque o homem sabe contar e as bestas, não. Se, por-|tanto, tão mínima parte de tais disciplinas, (que é o saber contar), | por ser comum à todas, o torna diferente dos demais animais, | lhe previlegiando com o nome racional. Fica claro, portanto, que quanto | mais aprendermos com estas, tanto mais seremos racionais e tanto mais | apartados estaremos dos [animais] irracionais.

26 Destas mesmas disciplinas, se coleta e leva (digo inad-|vertivamente) parte da Dialética, ou seja, da prática e do modo de | saber argumentar nas disputas, refutar o adversário, alcançando o | propósito de várias e diferentes maneiras, como esse procedimento | naquelas se manifestará. ${ }^{68}$

27 A força com que usou, Bartolo de Sassoferrato (famoso legista) na sua | [obra] Tyberina ${ }^{69}$ as figuras geométricas, manifestando, não somente ter sido | otimamente instruído nas Matemáticas, mas corroborando e advertindo a ne-|cessidade da geometria [na ciência] jurista.

28 O que diremos da guia e acompanhante da nossa saúde, | a sagrada Teologia. Não demonstra o Cardeal Nicolo de Cusa, na | penúltima parte de sua obra, entitulada Complementum theologicum | figurarum in Complementis Mathematicis, que sem a geometria, | não poderiam nossos intelectos se comunicar ${ }^{70}$.

29 Ainda mais, essa disciplina e ciência geométrica, não é tão | necessária, que não somente os homens mortais a usam para medir,| (como já foi dito muitas vezes anteriormente), mas | (5v) ainda o magnífico Senhor, que é a medida de todas as coisas. Na

\footnotetext{
${ }^{68}$ Este parágrafo fala da Dialética. Interessante notar se Tartaglia, está fazendo menção às ciências do trivium, ou uma alusão à teoria do conhecimento de Platão, na qual a Matemática é propedêutica à Dialética.

${ }^{69}$ Bartolo de Sassoferrato (1314-1357). Jurisconsulto medieval, comentador do Direito Romano e considerado um dos principais juristas do século XIV. Dentre sua obra está Tyberiadis D. Bartoli De Saxoferrato, lurisconsultorum Omnium Facilè Principis, Tractatus De Fluminibus (1355), obra de matéria jurídica específica, que versa sobre o regime das hidrovias. Este parágrafo se assemelha ao de Pacioli, Divina Proportione, porém lá está ligado à aritmética e a geometria, por estudo das inundações dos rios. (trad. Bertato, 2008, p.9)

${ }^{70}$ Nicolau de Cusa foi um estudioso (e cardeal) do séc. XV que circulou nas esferas políticas de Florença e Roma e tornou-se um personagem relevante nos estudos da história das tradições cristãs e neo-platônicas. Ele escreveu sobre teologia, filosofia, matemática, instrumentos de Astronomia, dentre outros tópicos. Ele aliou a matemática à teologia. Interessante notar que a primeira edição alemã da obra Dez livros de Arquitetura de Vitrúviu, de Walter Ryff, traz juntamente a obra de Cusa.
} 
formação | das partes do corpo humano, não se pode sem ela. É com ela, que estes | compositores de imagens e excelentes pintores se adaptam, a cada | membro utilizando-se do compasso. Pela [mesma] razão, os | peritos arquitetos, como manifesta Vitrúvio Polione, no primeiro | capítulo de seu terceiro livro, buscam com toda diligência propor-|cionar as casas e os demais edifícios (públicos e privados), à seme-|lhança do corpo humano, por ser aquele, como é dito pelo grande | arquiteto, ser feito com as devidas medidas ${ }^{71}$.

30 Finalmente se conhece a nobreza, excelência e grandiosidade | destas disciplinas, pela grande fama e nome daqueles, que se dedicaram | a estudá-las como foram [Hermes] Mercúrio Trismegisto, filósofo sacerdote e rei do Egito, | assim como Pitágoras, Platão, Plotino, Arquimedes de Siracusa, Apolônio Pergeo, | Jordano, Vitrúvio (Arquiteto), e tantos outros que aqui não terei tempo de mencionar. | Basta, para concluir, dizer que não se encontrará algum, que de grandioso nome e | fama reconhecidos não as tenha [não seja conhecedor das matemáticas].

31 Estas poucas palavras, eu quis propor neste nosso início, | para que vocês soubessem que a presente doutrina não é coisa | vã, nem mecânica, nem para ser desprezada. Mas, digníssima e | para ser apreciada por cada um; e, sem a qual, qualquer outra ciência | é imperfeita. Assim, por hoje terminaremos e amanhã começaremos a | declarar alguns termos pertinentes à nossa matéria.

32 Finalmente, para que eu não pareça ingrato à vossa boníssima | atenção e audiência, quer por sua prestosa humanidade, lhes rendo infinita gratidude.

\subsection{Segunda Lição}

\section{$(5 v)$}

1 Sendo o nosso propósito, Magníficos e Excelentíssimos audi-|tores, querer começar a inspirar, ou, a revelar essas | ciências, artes ou melhor, disciplinas, que os gregos chamavam de matemá-|ticas, e que em nossa língua não quer dizer outro, que ciências, ou artes doutri-|náveis. Para procedermos de forma ordenada, primeiramente definiremos quais

\footnotetext{
71 As relações proporcionais estabelecidas entre os membros do corpo humano e as partes nas edificações, aparecem nos comentaristas de Vitrúvio, mas devemos tomar cuidado com modificações posteriores, como a realizada por Daniele Barbaro (1556), que substituiu as proporções de caráter antropomórfico pelas proporções musicais. Podemos encontrar comentários que mesclam ambos os tipos de sistemas proporcionais. Vide: Bromberg, 2014b.
} 
| e quantas são estas tais ciências, ou disciplinas, e quais são os seus respectivos | objetos. Feito isso, distinguiremos a espécie de cada uma | delas e seus termos principais.

2 As ciências artes, ou disciplinas matemáticas, segundo o vulgo | são muitas: a Aritmética, a Geometria, a Música, a Astronomia, | a Astrologia, a Cosmografia, a Corografia, a Perspectiva, a Especulária | (6r) ou ciência dos Pesos; a Arquitetura e muitas outras. Contudo, Severino Boé-|cio e Giorgio Valla, seguindo a opinião de alguns [escritores] gregos, querem que sejam somente quatro as disciplinas matemáticas, | ou seja: a Aritmética, a Geometria, a Música e a Astronomia. E que | todas as demais sejam subalternas, ou seja, dependentes destas quatro.| Não obstante, Frade Luca dal Borgo prefere que as ditas discipli-|nas matemáticas sejam cinco (acrescentando às quatro acima defi-|nidas, a Perspectiva), ou que sejam três, excluindo, das quatro prece-|dentes, a Música. Para sustentar a sua opinião, oferece muitas razões | e argumentos, os quais, por não serem de grande importância, dei-|xaremos de lado. Até mesmo o Rev.mo Cardeal Sr. Pietro de Aliaco, na primeira questão sobre Giovanne de Sacrobusto, | conclui que a Música, a Astronomia e de forma similar a Perspectiva, | não são consideradas matemáticas puras (como é verdadeiro) mas, mate-|máticas médias, entre a matemática e a ciência natural ${ }^{72}$, sendo con-|sideradas puras somente a Aritmética e a Geometria. Todas as demais são | consideradas médias, dependentes ou mistas da matemática e da filo-|sofia natural. Exceção seja feita a Astrologia da adivinhação ${ }^{73}$, que é, quanto a |sua essência, por ele considerada puramente ciência natural.

3 Concluiremos então, que somente a Aritmética e a Geo-|metria, que são tratadas teoricamente por Euclides, são | consideradas matemáticas puras.

4 E porque, o primeiro livro do nosso autor, como foi dito | ontem, é de Geometria, e sendo o objeto da Geometria a quantidade | contínua, e cujas espécies, segundo o lógico, são cinco: | a linha, a superfície, o corpo, o lugar e o tempo ${ }^{74}$. Mas, que $\mid$ segundo o matemático são somente três: a linha, a superfície e o | corpo. E porque o mais puro e principal termo desta espécie de | quantidade é o ponto, nosso autor convenientemente o define | na sua primeira definição, dizendo:

\footnotetext{
${ }^{72}$ Nos tratados do século XVI é muito comum a ciência natural ser chamada de filosofia natural, o que equivaleria a nossa física.

${ }^{73}$ A Astrologia Giudiziaria é uma parte da Astrologia cuja finalidade é prever o futuro. No Vocabolario della Crusca aparece definida sob o termo Giudicatório, (4ed., vol.2, p.621) e Giudiciario (Lat. iudiciarius), (Gr.

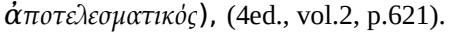

${ }^{74}$ O problema da noção de continuidade é tratado nas seguintes obras de Aristóteles, Categorias e Física. Lê-se nas Categorias: "[..] das quantidades, umas são discretas e outras contínuas [..] são quantidades contínuas a linha, a superfície, o corpo, e além destas o tempo e o lugar” (Categorias 6, 4b20-25).
} 
5 Punctus est cuius non est ${ }^{75}$. Ou seja, ponto é aquilo, a parte do | qual não é, isto é, que não se encontra como parte daquele, que em |essência não faz inferir outro, exceto que o ponto é aquilo que não tem parte algu-|ma, ou seja, do qual não se pode dar, nem tirar, nem achar, | nem imaginar a metade, \& não podendo tirar, nem dar um meio | ponto, menos ainda poder-se-ia tirar ou dar um meio terço, nem um meio quar-|to, nem qualquer outra parte semelhante a esta, pela qual definição se | denota, ser o ponto, indivisível e consequentemente não | ser uma quantidade, dado que toda quantidade contínua é capaz de ser dividida ao infinito.

6 Alguns poderiam dizer, por tudo o que você me disse | até agora, que eu não sei, nem entendo o que seja o ponto. (6v)

7 Ao que eu respondo, que cada qual de vós sabe, naturalmente, que coisa | ele é, e que sabe a verdade, que farei ser confessada a vós mesmos. Exempli gratia $^{76}$

8 Se eu pergunto, a qualquer um de vocês, como se chama a extre-|midade desta agulha, sem dúvida, cada qual de vocês dirá que se I chama ponta. Se eu vos perguntar, porque razão se chama | ponta, vocês me responderão, porque é assim sutilmente pontiaguda, e | que assim acabará em nada: se portanto, este término não será nada, | ele não é apto à divisão, isto é, não pode ser dividido em dois, nem | em tantas [outras] partes. No entanto, não havendo parte alguma, pela definição | do nosso Euclides, seria um ponto. Esta é a razão pela qual você | a chamou de ponta, portanto faz muito tempo que você sabe, | que coisa é um ponto.

9 Nas operações geométricas, este tal ponto é entendido e to-|mado por cada pequeno sinal feito voluntariamente ou acaso, | com qualquer estileto ${ }^{77}$, posto em qualquer espaço, desta forma, | ou com qualquer material colorido, como se faz com a pon-|ta da caneta sobre uma folha de papel, desta forma. Ou real-|mente com qualquer outro material colorido, como faria com este | gesso, deste modo.

10 Alguém pode dizer, que este ponto, artificialmente produzido, não | tem relação com o outro, como definido pelo nosso autor. Cuidado, pois | o operante geométrico nunca pode constituí-lo, nem marcá-lo tão pequeno, | que não possa ainda ser diminuído. Ou, que o intelecto não saiba ser divisível.

\footnotetext{
${ }^{75}$ Tomás de Aquino, Summa Theologica, I, q.10, a.1: (...) Ad primum ergo dicendum quod simplicia consueverunt per negationem definiri, sicut punctus est cuius pars non est.

${ }^{76}$ Por exemplo (locução adverbial).

${ }^{77}$ Estileto, verbete "stile" (Lat. stylus): Instrumento afiado e fino, normalmente feito de latão com o qual desenhavam os pintores. Vocabolario della Crusca, 1 ed, pg. 849.
} 
11 Eu mesmo considero que, dentre aqueles nobres, que são próximos a vós, | magnificissimos e ilustríssimos Auditores, possuam a obra do nosso Euclide, segundo | a tradução de Campano e outros, talvez, segundo a tradução feita por Bartholomeo | Zamberto, veneziano (que ainda está vivo). Alguns outros, tenham talvez, | a publicação feita em Paris, ou a Alemã. Nesta última, foram incluidas | ambas as traduções mencionadas. Mas, de uma certa forma, qual [dessas] estaria mais apta a gerar confusão no estudante, do que o contrário (como, claramente faremos conhecer em nosso processo). Outros ainda devem possuir a | nossa tradução, feita em lingua italiana. De modo que, com tanta variedade, para que | algumas pessoas não fiquem depois confusas, parecia querer repetir, breve-|mente a lição inteira de ontem, de acordo com cada uma das tra-|duções. Para que assim, se visse a diferença entre elas, o que não | seria inútil aos jovens principiantes. A partir disto, podem-se declarar, | ao menos, outras duas definições.

\section{Transcrição}

\subsection{Primeira lição}

\section{(fol.3r)}

\section{LETTIONE DE NICOLO \\ TARTALEA BRISCIANO,}

\section{SOPPRA TUTTA LA OPERA DI EVCLIDE}

\section{MEGARENSE, ACVTISSIMO MATHEMATICO}

Tutti gli huomini, Magnifici e Preclatissimi Au-|ditori, (come scrive Aristotele nel primo della | Methaphisica) naturalmente desiderano di sa-|pere, \& nel primo della posteriora conchiude, che | Il sapere non è altro, che intendere per demostra-|tione. Platone poi diffinisce la sapientia non es-|ser altro, che una cognitione delle cose divine \&/humane; \& tutti gli antiqui Philosophi dicono, le | parti della sapien-|tia ${ }^{78}$ esere due, cioè speculatione, \& operatione, over Theorica, \& Pra-|tica ${ }^{79}$ : Et Aristotele nel secondo della Methaphisica dice, che'l fine del-|la Speculatione, over della scientia speculativa non è altro, che la ve-|rità, \& della operatione, over pratica, è l’opera compita: Anchora li $^{80} \mid$ detti antiqui investigatori ${ }^{81}$ delle cose affermano come si tocca piu $l{ }^{82} \downarrow$ verità nelle Mathematice

${ }^{78}$ 1543, [et molti philosophi determinano]

79 1543, [over prattica e theorica]

${ }^{80} 1543$, [et tutti]

${ }^{81} 1543$, [Discrutattori]

${ }^{82} 1543$, [toccarse piu la] 
discipline, che in qualunque altra scientia ${ }^{83}$ over arte liberale: Per il che hanno assolutamente determinato quel-|le esser nel primo grado di certezza: \& pero vediamo (come dice il | Cardinal di Cusa) tutti quelli, che gustano di queste discipline ${ }^{84}$, acco-|starse a quelle con amor mirabile; \& questo non é per altro, se non | perche in quelle si contiene il vero cibo della vita intellettuale ${ }^{85}$.

2 Queste tali Scientie, over discipline sono state tanto intrinsicamen-|te conosciute da nostri favi antiqui, che da quelli fu determinato, | che la prima cosa che se dovesse far imparare a tutti quelli, che si de-|dicavano alla sapienza, fusseno le discipline mathematice (cioè, si co-|me al presente si costuma fare della grammatica). Et questa determi-|natione over costitutione serno per tre cause: Prima perche le dette | scientie, over discipline, approvano l'ingegno dell'huomo, se egli è | atto a far frutto nelle altre scientie, o nò: perche tra quelli si costuma-|va questo proverbio. Sicut aurum probatur ingni, \& ingenium Matematicis: cioè che si come la bontà del l'oro vien conosciuta, \& ap-|probata con il fuoco, cosi l'ingegno dell'huomo vien conosciuto \& | approvato con le Discipline Mathematice. Et pero quando per sor-|te trovavano alcuno, che dita i scientie non fusse capace, lo levava-|no da tal cominciato studio, \& lo applicavano ad altro esercitio, | perche in effetto comprendevano (come dice Vitruvio Polione al pri-|mo capo del suo primo libro) che la dottrina senza lo ingegno, ne lo | ingegno (fol.3v) senza la Dottrina, puo fare un perfetto artifice.

3 La seconda causa, perche li nostri antiqui volevano che le Mathe-|matice discipline fusseno le prime imparate, è questa, perche alla in-|telligenzia di quelle non vi occorre alcuna altra scientia. La causa è | che per se medesime si sostentano, per se medesime si verificano, per | se medesime si approvano, \& non per autorità, over opinione de huo-|mini, come fanno le altre scientie, ma per demonstratione.

4 La terza causa è, che conoscevano tutte le altre scientie, arti, over | discipline, haver delle Mathematice bisogno, \& non solamente le li-|berali, \& sue dependenti; ma anchora tutte le arte Mecanice, come | al presente sotto brevità, in parte si farà manifesto.

5 Primamente eglie cosa notta, che per mezzo di queste tai scien-|tie over discipline, nelle occorrentie naturali noi conoscemo in ma-|teria, la descriptione, qualità, \& quantità de ogni figura geometrica, | cioe de triangoli, quadrangoli, Penthagoni, Essagoni, Rhombi, \& | Rhomboidi, \& de ogni altra figura piana. Et similmente de ogni cor-|po solido, si regulare,

83 1543, [cioè nella Arithmetica et geometria]

${ }^{84} 1543$, [queste due discipline \& massime della geometria]

${ }^{85}$ A partir daqui a versão de 1565 se diferencia da de 1543. 
come irregulare, come sono pyramidi, prisme, | over seratili, sphere, coni, chilindri over colonne, cubi, ottobase, do-|dici base, vinti base, \& altri suoi dependenti, com tutte le sue proprie-|tà \& proportioni, come geometricamente descrive è forma el nostro | egregio Authore Euclide in 15. libri, delliquali 11. sono de geome-|tria, cioe el primo el 2.\& el 3.el 4. el 6. El 10. lo11. lo12. Il 13. Il 14. \& | il 15. Et tre sono di Arithmetica, cioè el 7. Lo 8. \& il 9. El quinto a | tutti questi è comune, il quale è della proportione \& proportionali-|tà, la qual proportione \& proportionalità cosi se aspetta al numero, come alla misura.

6 Certa cosa è anchora, che queste tai scientie, over discipline ma-|thematice sono nutrice, \& matre delli musici: Impero che con li nu-|meri \& sue proprietà proportione \& proportionalità noi conoscia-|mo la proportione dupla, che da pratici è detta ottava, esser compos-|ta d'una sesquitertia \& de una sesquialtera: \& similmente sapiamo | la sesquitertia esser composta de duoi toni, \& de un semiton menore, $\mid \&$ la sesquialtera esser composta de tre toni \& de un semiton meno-|re, per il che si manifesta la detta dupla, over ottava esser composta $\mid$ de cinque toni \& de duoi semitoni menori, cioè meno una coma de $\mid$ sei toni \& similmente sapiamo el tono esser piu di otto come $\&$ men|o di nuove. Anchora per vigor di queste tai discipline sapiamo esser impos-|sibile a dividere il detto tono, \& ogni altra superparticolare ratio-|nabilmente in due parti equale, il che dimostra il nostro Euclide, nel| la ottava propositione del ottavo libro.

7 Piu oltra, non per altra causa alli presenti tempi è penuria de bo-|ni \& eccellenti Astronomi, che per diffetto delle antedette discipli-|ne, (fol.4r) ne, perche di ben intendere l'Almagesto di Ptolomeo, \& similmente | Giovan de Monte Reggio senza le Euclideane Istruttioni, nium cer-|to si puo avantare: \& quantunque si lega nel Ecclesiastico al primo | capitolo. Altitudinem coeli, \& latitudinem terrae, \& profundu abis-|si quis dimensus est? Nondimeno tanta è la virtu di queste scientie, | over discipline, che per mezzo delle proportioni, non solamente li $\mid$ nostri antiqui hanno conosciuto quanta sia la rotondità di tutta la | terra, \& quanto sia el Diametro suo \& similmente delli altri elemen-|ti: ma anchora hanno conosciuto la grandezza del Sole, \& della Lu-|na, delle stelle, si fisse come erratice, \& la conversatione del loro Cie-|lo, come dimostra Ptolomeo nel Almagesto, \& Alphonso nelle sue | Tavole.

8 Queste medesime scientie over discipline, danno la via all'arte | Giudiciaria, detta astrologia, \& similmente alla Pyromantia, Hydro-|mantia, Geomantia, Nicromantia, \& altri sorti legi, come scrive Isi-|doro, \& Cieco Dascoli, \& similmente, Cornelio Agrippa nel secon-|do di Occulta Philosophia. 
9 Che diremo della Geographia? Non ci dimostra Ptolomeo \& tut-|ti gli altri e eccellentissimi Geographi, quanto li sia necessario el nu-|mero, la misura, la proportione, \& proportionalità. Quando che di | tutto l'universo debitamente proportionando li gradi della lor lon-|ghezza \& larghezza, in una picol carta, tutte le famose provincie, cit-|tà, castelli, monti, fiumi, isole, peninsule, \& altri siti maritimi, \& me-|ditterranei ci hanno ridotto.

10 Quanto che queste siano necessarie alla Corographia, cioè al mo-|do di mettere rettamanete in disegno un particolar sito, over paese, \& | similmente la pianta de una città lo habbiamo dimostrato nel quin-|to libro delli nostri quesiti, \& invention diverse.

11 Anchora considerando bene, e studiando la scientia Perspettiva, | senza dubbio si troverà che nulla sarebbe, se la Geometria, come ma-|dre sua, non se gli accomodasse. Questo non solamente ci verifica el |nostro Euclide, nella sua Specularia \& perspettiva, \& similmente lo | Arcivescovo Giovanne Cantuariense: ma piu abondantemente Vi-|teleone, quel gran Perspettivo, il quale ogni sua propositione appro-|va \& dimostra con le Euclideane propositioni.

12 Che queste scientie over Discipline siano necessarie all'arte Pit-|toria, non voglio star a provarlo particularmente, perche mi basta | che Alberto Duro alli tempi nostri pittor eccellentissimo, nella ope-|ra sua non solamente lo contessa \& affirma: ma ancora attualmente lo dimostra al senso.

13 Quanto queste siano opportune all'arte horologica, cioè alla com-|positione, descritione, over costruttione delli horologij, si horizon-|tali (fol.4v) tali come murali. Sebastiano Mustero non solamente in Pratica, ma |in Theorica lo fa manifesto.

14 Da queste medesime discipline germoglia, \& nasce la scientia de I Pesi, comi apertamente dimostra Giordano in quello de Ponderi-|bus, il che medesimamente retificamo \& approviamo nel quinto li-|bro delli nostri quesiti \& inventioni diverse, com la qual Scientia Aris-|totile nelle sue questioni Mecanice assegna la causa di ogni ingenio-|sa mecanica inventione.

15 Tanto è generale la virtu, over potentia di queste tai discipline | piene di certezza, che Archimede Siracusano per lo studio di quelle, | con suoi mecanici ingegni difese un tempo la citta di Siracusa con-|tra l'impetto di Marco Marcello Consule Romano, per il che acquis-|tò il nome della immortalità.

16 Per mezzo di queste si fanno varij \& diversi modelli, fabricansi pon-|ti quasi alla natura impossibile. 
17 Anchora se con lo intelletto ben considranno \& guardanno tutte | le sorte de antique \& moderne machine, \& istromenti belici si offen-|sivi come distensivi, come sono bastioni, repari, bricole, trabocchi, | catapulce, scorpioni, baliste, ariete, restudine, helepoli, (come dimos-|tra Vetruvio nel decimo). Et similmente Vegetio, Valturio, \& Lion | Battista delli Alberti, sempre con forza de numeri \& misure le loro | proportioni si trovano formate \& fabricate.

18 Delle nove inventioni per noi trovate, sopra el tirar delle moder-|ne machine tormentarie, dette dal vulgo artegliarie, non voglio re-|plicarlo per haverlo altrove detto \& in parte publicato: basta sola-|mente a dire, che per consiglio di queste, senza alcuna sperienza ne | pratica in tal esercitio la maggior parte ritrovai.

19 Similmente per virtu di queste habbiamo ancor trovato di man-|dar a esecutione tutti quei modi (recitati da Vegetio, \& da Fronti-|no Valturio), che usavano li nostri antiqui nell'ordinare gli eserciti | in battaglia sotto varie \& diverse forme, cioè in forma quadra di gen-|te, over di terreno, \& similmente el modo di formar, el cuneo, la for-|fice, la sega, el rhumbo, la forma circulare e la lunare, le qual cose alli |presenti tempi quasi in tutto sono perdutte.

20 Di quanto aiuto et subsidio sian le dette discipline alla Architet-|tura, Vitruvio Polione nel suo proemio lo fa manifesto.

21 Queste tai scientie, over discipline non solamente acuisseno l'in-|gegno del huomo, \& lo fanno atto a poter con facilità penetrare in | qual si voglia altra scientia: ma anchora lo preparano a poter agil-|mente discorrere over caminare di longo alla sapientia: Anzi che Bovetio Severino vol che queste tai scientie, over discipline siano le pro-|prie vie di ascendere a quella, \& finalmente conciude senza queste | tai (fol.5r) scientie overo discipline esser impossibile di potere rettamente filosofar.

22 Questo medesimo vienne a essere stato retificato com li effetti da | quel Platone padre e maestro de Philosophi, el quale non voleva che | alcun scholaro intrasse nella sua schola, over studio, se non era prima | in geometria ben isperto.

23 Et pero non è da maravigliarsi, se molti passi nella Phisica, Metha-|phisica, \& Posteriora de Aristotele, \& similmente in quel de Celo \& | mundo paiono oscuri, \& difficili alli nostri moderni, che la maggior | parte non procede da altro, che per non sapere predette discipline. 
24 Queste medesime danno l'essere alla Pratica speculativa di Alge-|bra, \& Almucabala, volgarmente detta la Regola della cosa over ar-|te Magna, e queste, non solamente Maumeth figliuolo de Moise Ara-|bo (gia di tal scientia primo inventore). Ma anchora frate Luca dal | Borgo, Michel Stifelio e Leonardo Pisano Geometricamente lo fan-|no manifesto.

25 Essendo un giorno interrogato il divino Platone, perche causa lo | huomo fra el genere de gli animali era chiamato animal rationale, | \& tutti li altri erano detti irrationali \& brutti, lui rispose perche lo $\mid$ huomo sa numerare $\&$ le bestie non. Se adunque cosi minima parte | di tai discipline (che è numerare) per esser comune a tutti, ne fa dif-|ferenti da gli animali brutti, \& ne previleggia di questo nome ratio-|nale; Eglie adunque cosa chiara che quanto maggior parte appren-|diamo di quelle, tanto più faremo rationali, \& lontani dalli irra-| tionali.

26 Da queste medesime discipline se raccoglie \& prende (dico inave-|dutamente) parte della Dialettica, cioè la prattica $\&$ il modo di sa-|pere argomentare nel disputar le cose, \& a confutare lo aversario, \& $\mid$ conchiudere il proposito per varie \& diverse vie, come che proceden-|do in quelle si farà manifesto.

27 Piu forte Bartolo da Sassoferrato (famoso legista) nella sua Tybe-|rina sue figure geometrice usando, non solamente ne manifesta lui | essere stato nelle Mathematice ottimamente instrutto \& corroborato, | ma anchora ne advertisse la geometria esser necessaria in iure.

28 Che diremo della guida \& scorta di nostra salute sacra Theolo-|gia: Non dimostra il reverendissimo Cardinal Nicolo di Cusa nel-|la penultima parte de l'opera sua, senza la geometria non potersi a-|gli intelletti nostri communicare, la qual parte è intitolata Comple-| mentum theologicum figurarum in Complementis Mathematicis.

29 Ma eglie di tanta necessità questa geometrica disciplina \& scien-|tia, che non solamente noi huomini mortali nelle nostre cose com-|mensurabili usano quella, come piu volte è stato detto, ma ancho-|ra il (fol.5v) magno Iddio, il quale è misura di tutte le cose, in formar le par-|ti del corpo humano, non si governa senza quella, con la quale, ancho-|ra questi Compositori de imagini, \& pittori eccellenti si conforma-|no, ad ogni membro usando el suo compasso: per il che anchora li pe-|ritissimi Architetti, come ci manifeta Vetruvio Polione al primo | cap. del suo terzo libro. Cercano con ogni diligentia di proportionare | le case \& altri suoi publici \& privati edifici alla similitudine del det-|to corpo humano, per esser quello, come è detto, dal sommo Archi-|tettore com debite misure fabricato. 
30 Finalmente conosce anchora la nobilità, eccellentia \& altezza | di queste discipline, per la gran fama \& nome di quelli, iquali han-|no dato opera ad essornare \& studiare dette scientie, come furno Mer-|curio Termegisto philosopho sacerdote \& Re d'Egito, similmente | Pythagora, Platone, Plotino, Aristotele, Averois, Hypocrates, el nos-|tro Euclide, Ptolomeo, Archimede Syracusano, Apollonio Pergeo, | Iordano, Vitruvio Architetto. Et molti altri, iquali per brevità las-|so, per non vi tenir in tempo, basta in conclusione, che non si trovarà | alcuno che sia stato di gran nome \& fama in alcuna facultà senza le | Mathematice.

31 Queste poche parole ho voluto preponere in questo nostro prin-|cipio, accioche voi conosciate che la presente dottrina non è cosa vi-|le, ne mecanica, ne da essere spreciata, ma dignissima \& da esser ap-|precciata da ogn'uno, senza la quale ogni altra scientia è imperfetta, | \& cosi per oggi faremo fine, dimane poi cominciaremo a dechiari-|re alcuni termini alla materia nostra pertinenti.

32 Finalmente accio che non para che io sai ingrato della benignissi-|ma attione \& audentia, che per vostra humanità me haveti presta-|ta. Vi rendo infinite gratie.

\subsection{Segunda lição}

(5v)

Seconda Lettione

1 Essendo il proposito nostro Magnifici \& Eccellentissimi audi-|tori, di voler dar principio a isponere, over dechiarare quelle | scientie, arti over discipline, che da Greci sono dette Mathema-|tice, che in nostra lingua non vol dir altro che scientie, over arti dottrinabile; per procedere regolatamente, prima diffiniremo quale, | \& quante siano queste tai scientie, over discipline, \& qual sia il loro | proprio sogetto: Et da poi questo, distingueremo le specie di cadau-|na di quelle, \& li suoi termini principali.

2 Le scientie Arti, over Discipline Mathematice, secondo il vulgo | sono molte, cioè Arithmetica, Geometria, Musica, Astronomia, | Astrologia, La Cosmographia, La Corographia, La Perspectiiva, la Spe-|cularia (6r), la scientia di pesi, la Architettura \& molte altre: ma Bove-|tio Severino, \& Giorgio Valla tolendo tal opinione da alcuni Gre-|ci vogliono, che le dette discipline Mathematice siano solamente quat-|tro, cioè Arithmetica, Geometria, Musica, \& Astronomia, \& che tut-|te le altre siano subalternate, cioè dependenti dalle dette quattro: | Ma Fra Luca dal Borgo San Sepulchro, vuole che le dette discipli-|ne Mathematice siano overamente cinque (aggiongendo alle pre-|dette quattro la Perspettiva) overamente tre, iscludendo dalle pre-|dette quattro la Musica: \& per sostenare tal sua opinione, aduce ra-|gioni \& argumenti assai, li quali per non esser cosa de importantia la- 
sciaremo da banda. Nientedimeno il Reverend. Sig. Pietro de Alia-|co Cardinale, nella prima questione sopra Giovanne di Sacrobusto, | conchiude, la Musica, \& la Astronomia, \& similmente la Perspettiva | non esser pure Mathematice (come é il vero) ma medie fra le mathe-|matice, \& la scientia naturale: per il che seguita solamente la Arith-|metica, \& la Geometria esser le pure Mathematice, \& tutte l'altre es-|ser medie, over dependenti, \& miste delle Mathematice discipline \& |della scientia naturale, eccettuando la Strologia giudiciaria, la qual | egli conchiude esser pura naturale, in quanto alla sua essentia.

3 Concluderemo adunque che solamente la Arithmetica, \& la Geo-|metria, delle quali speculativamente tratta el nostro Euclide, siano | le pure discipline Mathematice.

4 Et perche il primo libro del detto nostro Authore, come fu detto | hieri, è di geometria, il sugetto della quale geometria è la quantità | continua, le specie della qual quantità continua, secondo el logico | sono cinque, cioè, linea, superficie, corpo, luogo \& tempo. Ma secon-|do il mathematico sono solamente tre cioè linea, superficie, \& cor-|po. Et perche il piu puro \& principal termine di queste tai specie de | quantità è il ponto, pero convenientemente il nostro Authore ne |difinisse quello nella sua prima diffinitione. Dicendo.

5 Punctus est cuius pars non est. Cioè il ponto è quello, la parte del | quale non è, cioe che non si trova parte di quello, che in sostantia non-|vol inferire altro, salvo che il ponto è quello, che non ha parte alcu-|na, cioè che di quello non si potria tuor ne dar ne trovar |ne imaginar un mezzo ponto, \& non potendo tuor ne dar un mezzo | ponto, meno potremo tuor ne dare un mezzo terzo, ne un mezzo quar-|to, ne alcuna altra parte simile a quello, per la qual diffinitione ne | dinotta il detto ponto esser indivisibile, \& consequentemente non lesser quantità, perche ogni quantità continua è divisibile in infinito.

6 Alcuno potrebbe dire, per tutto quello che tu me hai detto fin a | questa hora, io non so ne intendo che cosa sia questo punto. (6v)

$7 \quad$ Et io rispondo, che cadauno de voi per natural istinto sa che cosa | eglié, \& che sai il vero, lo farò confessare a voi medesimi. Essempli | gratia.

8 Se io adimando a qual si voglia di voi, come se chiama la istremi-|tà di questo ago over gucchia, senza dubbio cadauno di voi dirà che / se chiama ponta, se vi adimandarò perche ragione se chimela cosi | ponta, voi me rispondereti, perche è cosi sutimente appontita, \& che | va cosi a terminare in niente: se adunque tal termine sarà niente, el | non receverà divisione, cioè chel non si potra dividere in due ne in | piu parti, \& pero non haveria parte alcuna \& non havendo parte per | la diffinitione del nostro Euclide saria un punto, \& questa è la ragio-|ne che voi la chiamati ponta, adunque eglie tempo assai che voi sa-|peti che cosa è ponto.

9 Questo tal ponto nelle operationi geometrici si intende \& piglia | per ogni picol segno fatto voluntariamente over a caso com qualche | stiletto pontito in qualche spacio, come faria a questo modo) ove-|ramente con qualche materia colorata, come saria a dire con la 
pon-|ta de la penna in qualche foglio di carta a questo modo. Overamente, | con qualche altro material colore, come faria con questo gesso a | questo modo.

10 Alcun potria dire, questo tal ponto artificialmente fatto, non ha-|ver alcuna convenientia con quello, che diffinisse lo Authore, atten-|to che lo operante geometrico mai non lo puo costituire ne segnar | talmente picolo, che non possa esser sempre piu picolo, over che non | sia sempre divisibile appresso all'intelletto.

11 Considerando fra me medesimo Magnifici \& Preclarissimi Audi-|tori qualmente alcuni delle nobiltà vostre hanno appresso di se l'o-|pera del nostro Euclide secondo la prima tradutione dal Campano, | \& alcuni altri secondo la seconda, fatta da Bartholomeo Zamberto | Veneto (che vive anchora). Alcuni altri secondo la stampa di Pari-|s e, over d'Alemagna, nella quale hanno incluso le predette ambedue | tradutioni, ma per un certo modo qual è piu presto atto a generare | confusione in cadauno studente, che altramente, (come nel nostro pro-|cesso faremo chiaramente conoscere) \& alcuni altri l'hanno secon-|do la nostra traduttione fatta in volgare, $\&$ accio che per tal varia-|tione alcun dipoi non resta confuso, ne ha parso di volere sotto bre-|vità repettere tutta la lettione de hieri secondo cadauna de dette tra-|dutione, accioche si veda la differentia che sia da l'una a l'altra, \& la | qual cosa non sarà inutile alli giovani principianti: da poi questo se | dichiarirà anchora, almeno le due altre seguenti diffinitioni. 